\title{
Revisiting Synchronous Computer-Mediated Communication: Learner Perception and the Meaning of Corrective Feedback
}

\author{
Hye Yeong Kim ${ }^{1}$ \\ ${ }^{1}$ English Language and Literature, Sungkyunkwan University, Seoul, Korea \\ Correspondence: Hye Yeong Kim, English Language and Literature, Sungkyunkwan University, Seoul, Korea. \\ Tel: 82-2-760-0263. E-mail: khytesol@gmail.com
}

Received: June 25, 2014 Accepted: July 26, 2014 Online Published: August 14, 2014

doi:10.5539/elt.v7n9p64 URL: http://dx.doi.org/10.5539/elt.v7n9p64

\begin{abstract}
Effectively exploring the efficacy of synchronous computer-mediated communication (SCMC) for pedagogical purposes can be achieved through the careful investigation of potentially beneficial, inherent attributes of SCMC. This study provides empirical evidence for the capacity of task-based SCMC to draw learner attention to linguistic forms by offering opportunities for corrective feedback and incidental recasts, highlighting learners' errors. The findings open up the discussion on the meaning of feedback considering learners' perceptions and the unique SCMC features. The findings indicate that learners do not attend to corrective feedback that promote "the corrector" and "the corrected" relationships. Rather, they benefit from incidental recasts that coincidentally contrast with their ill-formed L2 production. This study also challenges the previous assumptions regarding certain SCMC features believed to be beneficial to learners. Features like split turns increase learners' cognitive load and make it difficult for learners to follow the flow of the conversation. Considering split turns of SCMC and learners' different perceptions on tasks, this study calls for reframing recasts in SCMC and more sensitive research methods for investigating SCMC interaction.
\end{abstract}

Keywords: synchronous computer-mediated communication (SCMC), linguistic feedback, learner perception

\section{Introduction}

The use of computer-mediated communication (CMC) has increased both inside and outside of classrooms as computers and the Internet has become increasingly accessible (DeBell \& Chapman, 2006). In the field of second language acquisition (SLA), synchronous CMC (SCMC) has drawn significant attention from teachers and researchers as a socially mediated form of instructional activity. This meaningful, socially constructed, and motivating form of communication aligns with current theoretical and pedagogical trends in SLA. Moreover, a growing number of studies have proven the benefit of SCMC for SLA, suggesting that SCMC promotes interaction among learners and attention to linguistic input, which are thought to be central to the social and cognitive concerns of SLA (Kim, 1998; Warschauer, 1996).

To explore the role of SCMC as a new language-learning tool, many studies grounded in interactional theory have investigated SCMC, focusing on the types of interaction, linguistic feedback, and learner uptake in responding to feedback (e.g., Lai \& Zhao, 2006; Pellettieri, 2000; Smith, 2003). However, most of these interactional studies have investigated SCMC as a cognitive process, failing to pay attention to social factors' influence on learning processes. Criticizing the limitation of interactional studies in face-to-face situations, Tarone (2009) claimed that "attention is not just a cognitive process, but rather is sociocognitive in nature, in that social factors such as audience and formality of the social context affect the amount of attention paid to language form" (p. 43). In other words, the social context can influence learners' attention by mediating how input, output, and feedback work for SLA.

Although Tarone (2009) did not intend to include computer assisted language learning (CALL), her criticism of the limitation of the interactional approach should be considered in CALL research. SCMC is different from face-to-face interaction and a relatively new context of interaction. The interlocutors during SCMC are not physically present in the same place and use text to interact. In addition, learners may have different expectations of SCMC, which might lead to different learning experiences. This interaction environment means that the kind of input, output, and attention paid during SCMC can differ from those in face-to-face conversation. Therefore, it is important to investigate SCMC as a new social context in order to understand how learners make use of 
SCMC for SLA rather than applying the same definitions and methodologies used in face-to-face conversation to SCMC environments. This paper explores the kinds of learning environments that SCMC provides for learners and revisits the meaning of feedback between English as a second language (ESL) learner during SCMC.

\section{Literature Review}

\subsection{SCMC and Learner Uptake}

As a way to investigate the effect of SCMC interaction on learners' attention to forms and SLA, learner uptake - namely, learners' immediate response to interlocutors' feedback - has often been examined in studies of face-to-face interaction. For example, Iwasaki and Oliver (2003) found that approximately 23 percent of corrective feedback led to learner uptake in their study; this is considered a relatively low rate compared to the uptake rate found in face-to-face interactions. Loewen and Erlam (2006) reported only 9 percent of uptake in a study with 31 elementary-level second language learners. A low rate of learner uptake may suggest that SCMC is not an ideal site to expect SLA through interaction.

However, the findings on learner uptake related to corrective feedback are less conclusive. Some studies have reported a higher rate of uptake during SCMC. For example, in a study of interaction between native speakers of Italian and non-native intermediate learners, Tudini (2007) found a particularly high level of uptake -59 percent. In her study, the dyads consisted of native and non-native groups, indicating that learners might have concentrated more on the feedback from native interactions than from non-native peers. The mixed findings on learner uptake suggest that SCMC environments, compared to face-to-face conversations, may be more sensitive to different factors, such as task types, learner proficiency, learners' previous experience with SCMC, and interlocutors' relationships. In addition, such findings suggest that learner uptake during SCMC may not be a reliable method to investigate if learners noticed linguistic forms or learned them.

The reliability of uptake as a measurement of noticing or learning is in question. Learners' immediate response - rather than indicating their recognition of error feedback - may instead simply show the ability to mimic the interlocutor's utterance. Successful repair does not always indicate that the learner has perceived the recast as corrective feedback (Ellis \& Sheen, 2006). Rather, the learner may have perceived the recast as a paraphrase intended to confirm content. Instead of noticing the gap between their incorrect utterance and the recast, learners may simply repeat the interlocutor's recast as a means of participating in the conversation. Therefore, uptake may occur, but not acquisition. Moreover, noticing does not always lead to uptake as uptake occurrence depends on conversational contexts (Oliver \& Mackey, 2003; Sheen, 2004).

The uptake as a measurement for noticing seems more problematic in SCMC considering the unique features of this communication mode. SCMC may not provide the best interactional environments to encourage learner uptake. For instance, even when learners notice recasts, they may feel less need to respond to the feedback, as they would have to retype their "utterance," which could feel unnatural and redundant compared to similar situations with oral feedback. Therefore, research results based on only learner uptake cannot provide a full picture of the effect of SCMC on SLA. Similarly, Smith (2005) suggested a possible diminished role for uptake in SLA in CMC environments. Smith explored the relationship between negotiated interaction and learner uptake during SCMC among intermediated-level learners of English. He found high levels of uptake in a study with 12 ESL dyads. Indeed, approximately 42 percent of lexical corrections led to successful learner uptake. Smith also determined that no relationship existed between the degree of uptake and the acquisition of target lexical items. Thus, replying only on learner uptake may not tell us how learners make use of corrective feedback during SCMC.

Although most existing studies rely on learners' immediate response as uptake, a few studies have used stimulated recall method to triangulate the data. Lai and Zhao (2006) compared the amount of noticing recasts and negotiation during SCMC and face-to-face interaction among six ESL dyads. The researchers found that 10 out of their 12 participants were able to notice some negotiation episodes while 6 participants noticed negotiation episodes during SCMC more often than during face-to-face interactions, even though the differences were not statistically significant. Furthermore, Lai, Fei, and Roots (2008) found that 46 percent of all recasts were noticed using stimulated recall data in a study with 17 ESL learners. In particular, learners noticed contingent recasts significantly more often than non-contingent recasts. Such findings suggest that the split turns can make it hard for learners to notice recasts.

The mixed findings on learner uptake suggest that it is premature to conclude the effect of SCMC on SLA without accumulating further studies in different contexts. Given the unique SCMC features, a more systematic investigation is necessary to explore how learners perceive corrective feedback during SCMC. This paper attempts to explore the extent to which the interaction during SCMC pushes learners to attend to L2 forms using 
different data sources - namely, SCMC transcripts, SCMC recording, stimulated recall, and survey. In particular, this study will examine learners' response to corrective feedback and perception of corrective feedback during online conversation. To this end, the following questions will be answered:

1) What kinds of corrective feedback are offered during text-based synchronous online interaction?

2) How do ESL learners perceive corrective feedback?

3) To what extent and how do learners pay attention to linguistic forms?

\section{Methodology}

\subsection{Participants}

Participants included intermediate-level ESL students from two different ESL classrooms at a large public university in the United States. Individuals participated in the study as part of their regularly scheduled ESL classes ( $\mathrm{n}=28,12$ females and 16 males). Eight languages (Arabic, Afaan Oromo, Ethiopian, Chinese, French, Korean, Malay, and Vietnamese) were represented. Learners completed a background questionnaire, on which they reported similar previous experience with computers. Most participants reported regularly using computers for sending email, word processing, web surfing, and chatting. Many students had experience using online chatting in their native languages rather than in English. However, they were all comfortable typing in English.

\subsection{Data Collection}

Data were collected from three sources: online chat, stimulated recall protocol, and survey. First, ESL students were paired up to participate in task-based online conversations. The participants completed spot-the-difference tasks in which dyads examined pairs of pictures that were almost identical except for a couple of differences. Participants were informed of the number of differences so that they could work together to reach the goal. Participants could see their partners' pictures. Both interlocutors needed to request and supply the information to each other in order to complete the tasks. The spot-difference-task was chosen because such a task was believed to facilitate negotiated interaction (Pica, Kanagy, \& Falodun, 1993). In addition, such a task has been used in previous ESL research on negotiated interaction (e.g., Mackey, Gass, \& McDonough, 2000). The popularity of the task in face-to-face interaction research helped researchers more easily understand the extent to which interactions via SCMC were different from or similar to face-to-face interactions based on the findings from previous research. The online chats were recorded with screen capture for the analysis.

The second method used to elicit data was stimulated recall. Stimulated recall is a method of introspection that aims to explore the learner's thought processes and strategies involved in carrying out a task or activity (Gass \& Mackey, 2000). Gass and Mackey claimed that not all processes involved in learning are directly observable. Therefore, although the learner's language production data - which have been a main source of SLA research - can describe the actual knowledge of the second language, it cannot provide understanding of how that knowledge comes about. The stimulated recall methodology can be used to determine such underlying linguistic knowledge.

The stimulated recalls were conducted immediately after the online chat to capture learners' perceptions during the tasks before the memory faded away; the stimulated recalls were also audiotaped. After the online chat session, the researcher and participants reviewed the script of the online conversations, during which time the researcher directed the learner to each point in the conversation where feedback was provided and asked the learner to recall his or her thoughts at that time. The researcher used undirected verbal prompts (e.g., "What were you thinking when you typed/wrote that?", "Why did you say that?", "What did you intend to say?", "What were you paying attention to at that moment?") and passively listened to the learner's recall. The participants were also encouraged to direct the researcher's attention to any particular point of conversation at any time if they wanted to describe their thoughts about it.

Finally, participants filled out a survey with questions about their backgrounds, including their previous experience with computers. Participants were also asked to share their thoughts on the SCMC tasks and perception on feedback and errors during SCMC.

\subsection{Procedure}

The procedure is summarized in Table 1. Participants first completed a practice task during which they carried out similar tasks as those used in the study, interacting via online the chat tool Microsoft Window Messenger. The tasks were explained in detail to participants during the practice session. Participants were told that they and their partners had pictures with slight differences; they had to use online communication to identify those differences. Participants were told how many differences were in the pictures before starting the actual tasks. 
They were also told to actively ask questions and answer their partner not only to identify the differences in the pictures, but also to figure out unfamiliar words related to the pictures. After the practice sessions, an ESL student was paired up with another ESL student for online chat. The scripts of online chat were recorded. After completing tasks via the online chat, ESL students participated in a stimulated recall session. The stimulated recall methodology was used to elicit learners' perceptions about the feedback at the time when the CMC interaction was in progress. The tasks and times spent on tasks are outlined in Table 1.

Table 1. Procedure and approximate times for dyads

\begin{tabular}{ll}
\hline Procedure & Average time spent \\
\hline Practice task & $10-15 \mathrm{~min}$ \\
Online task session & $50 \mathrm{~min}$ \\
Stimulated recall training + stimulated recall & $40 \mathrm{~min}$ \\
\hline
\end{tabular}

\subsection{Analysis}

The online chat was transcribed and coded for instances of negotiation of meaning, corrective feedback, and self-correction. Interactional feedback was analyzed by type, frequency, and response rate. In particular, recasts were analyzed according to the target of recasts and the recall rate. Recasts were operationalized as episodes in which interlocutors corrected partners' ill-formed utterances implicitly without interrupting the flow of the communication. Self-corrections were episodes in which the participants corrected their own mistakes immediately without any help from their interlocutors. The interrater reliability on coding of accuracy of recasts was 95 percent. Table 2 summarizes the definitions and examples of terms encountered during the procedure. Table 3 provides examples of noticing and not noticing.

Table 2. Definitions and examples of terms

\begin{tabular}{|c|c|c|}
\hline Term & Definition & Example \\
\hline Negotiation & $\begin{array}{l}\text { Exchanges that begin with an explicit indication of } \\
\text { non-understanding and that result in a temporary "push } \\
\text { down" in the conversation, away from the main line of } \\
\text { discourse }\end{array}$ & $\begin{array}{l}\text { NS: Maybe one girl. Ponytailed hair } \\
\text { NNS: Yes } \\
\text { NS: And wearing a skirt. And walking } \\
\text { NNS: My picture is doing } \\
\text { NS: Doing? With what? } \\
\text { NNS: Ball }\end{array}$ \\
\hline $\begin{array}{l}\text { Explicit } \\
\text { feedback }\end{array}$ & $\begin{array}{l}\text { Explicit correction provides learners with a correct form } \\
\text { with a clear indication of what is being corrected. }\end{array}$ & $\begin{array}{l}\text { NNS1: The snow man wears scof. } \\
\text { NNS2: Scof? Nono. scarf. }\end{array}$ \\
\hline Recasts & $\begin{array}{l}\text { Target-like reformulations of ungrammatical utterances } \\
\text { that maintain the central meaning of the original utterance }\end{array}$ & $\begin{array}{l}\text { NNS: There is monkey. } \\
\text { NS: Yes. There is a monkey. }\end{array}$ \\
\hline $\begin{array}{l}\text { Linguistic } \\
\text { targets }\end{array}$ & Morphosyntax, lexis, semantics & $\begin{array}{l}\text { Morphosyntactic episode } \\
\text { NNS: There is a three bird my picture. } \\
\text { NS: Three birds in your picture? } \\
\text { Semantic episode } \\
\text { NNS: He is on the tree. } \\
\text { NS: He is standing on the tree? } \\
\text { Lexical episode } \\
\text { S: The sea and, the sea and ... } \\
\text { T:The lake and ... }\end{array}$ \\
\hline $\begin{array}{l}\text { Self } \\
\text {-correction }\end{array}$ & $\begin{array}{l}\text { Episodes in which the participants noticed and corrected } \\
\text { their own mistakes without any help from others }\end{array}$ & $\begin{array}{l}\text { S: It's another different } \\
\text { difference }\end{array}$ \\
\hline
\end{tabular}


Table 3. Noticing and not noticing

\begin{tabular}{lll}
\hline Attention & Corrective feedback & Stimulated Recall \\
\hline Noticing & $\begin{array}{l}\text { S 1: Guy and son man } \\
\text { have hat. }\end{array}$ & $\begin{array}{l}\text { Researcher: When you heard S2 said that "guy and } \\
\text { snowman have hat?" what were you thinking? }\end{array}$ \\
& $\begin{array}{l}\text { S2: Guy and snowman } \\
\text { have hat? }\end{array}$ & $\begin{array}{l}\text { S1: I think he was correcting my word, son man. He } \\
\text { maybe wanted to tell me that snowman is correct one. }\end{array}$ \\
No noticing & $\begin{array}{l}\text { S3: OK, it's the first } \\
\text { different }\end{array}$ & $\begin{array}{l}\text { Researcher: When you heard S4 said that "it's the first } \\
\text { difference," what were you thinking? }\end{array}$ \\
& $\begin{array}{l}\text { S4: Yes. It's the first } \\
\text { difference. }\end{array}$ & $\begin{array}{l}\text { S3: I thought he agreed with me. He thought that it was } \\
\text { different like I did. }\end{array}$ \\
\hline
\end{tabular}

\section{Results and discussions}

\subsection{SCMC and Corrective Feedback}

The data suggest that both explicit and implicit corrective feedback were offered during online interactions. Table 4 summarizes the types of corrective feedback found in this study. According to the data, corrective feedback was offered on all aspects of the grammar. Overall, more implicit feedback was provided than explicit feedback during the online interaction. Explicit feedback was not used in targeting morphosyntactic errors, and all explicit feedback targets were focused on lexical errors. In contrast, the majority of implicit feedback was focused on morphosyntatic errors. This finding corroborates the results of Lai and Zhao (2006), who demonstrated that the majority of implicit feedback was focused on morphosyntactic errors while explicit feedback focused on lexical errors. The data further indicate that the quality of feedback was good. Only 13 percent of the corrective feedback provided non-target forms as a model.

Table 4. Corrective feedback

\begin{tabular}{lllllll}
\hline Feedback types & \multicolumn{5}{l}{ Implicit } \\
\hline & Explicit & & & \\
\hline Direction & Target & Non target & Total & Target & Non-target & Total \\
\hline Lexical & $9(16 \%)$ & $2(3 \%)$ & 11 & $17(30 \%)$ & $3(5 \%)$ & 20 \\
Morph syntactic & & & & $24(41 \%)$ & $3(5 \%)$ & 27 \\
Totals & 9 & 2 & 11 & 41 & 6 & 47 \\
& & & & & 58 & \\
\hline
\end{tabular}

The response rate of recalling recasts in this study was low. Learners rarely immediately incorporated target-like recasts (7 percent). This finding contrasts with Pellettieri's (2000) results, which indicated that 75 percent of implicit feedback was incorporated by learners. The different results may stem from the differences in participants' proficiency levels and attitudes toward the tasks. The low response rate is most evident in the low noticing. As Table 5 demonstrates, the recall rate for implicit feedback was very low. Only 8 percent of recasts were recalled by students while 92 percent of recasts were not recalled during the stimulated recall session. The low response and recall rates suggest that learners in this study did not feel the need to pay attention to corrective feedback or respond to the recast because they were focused on the task rather than grammar. Once participants confirmed the content, they often moved on to the next topic.

Table 5. Stimulated Recall Rate

\begin{tabular}{lll}
\hline & Recalled & Not recalled \\
\hline Lexical & $4 \%$ & $96 \%$ \\
Morph syntactic & $4 \%$ & $96 \%$ \\
\hline
\end{tabular}

The findings in the current study indicate that most corrective feedback was given in implicit form, and was not 
recalled by learners during interview. It appears that the peer relationships influenced the feedback types or recall rate. As peers, explicit corrective feedback may not be socially acceptable. Accordingly, participants offer implicit rather than explicit feedback. However, in the case of lexical errors, it may be somewhat easier to give explicit feedback as it could sound like clarification for rather than correction of others. In addition, explicit feedback in part occurred relatively infrequently as participants' focus was on the task rather than learning grammar. Accordingly, correcting others' utterances may be marked in this situation. Furthermore, participants might not pay as much attention to feedback from a non-native speaker (NNS) as from native speakers. Students may feel more uncomfortable providing explicit corrective feedback in SCMC than providing it in face-to-face conversation because SCMC could sound less casual due to the text form. The low response rate of recalling recasts in this study also seems to stem from similar reasons. Regardless of the reasons, the findings suggest that SCMC may not be a good environment for learners in peer relationships to promote explicit corrective feedback.

\subsection{SCMC Features and Learner Attention}

The low recall rate of recast suggests that learners may not pay attention to linguistic forms during SCMC. This finding conflicts with prevailing assumptions regarding SCMC. It is often assumed that certain features of SCMC can offer better linguistic feedback to learners. For example, visual saliency is believed to help learners compare the target form with their utterance more easily (Pellettieri, 1999; Smith, 2004). In addition, the extra processing time is believed to be an added advantage of SCMC chat compared to oral conversations (Pellettieri, 1999). However, the current study demonstrates that learners do not benefit from these features in noticing corrective feedback.

During the interview, 85 percent of learners noted that they felt that they did not have enough time to think about their utterances twice. Instead, they felt the pressure to type something and to respond quickly without taking long pauses. One of the participants explained why he had not corrected his errors, although he knew that errors existed:

If I corrected it, my partner would say something else already, while I was correcting. Once I type a sentence, whether or not there was an error, she would either answer my questions if my sentence was a question. Or she would move on to another topic when my utterance was an answer to her previous utterances... She would not think that I was retyping same sentences to correct errors.

This common concern of overlapping turns during SCMC also explains why learners' language is often fragmented. Participants often used several lines to type a sentence, as the following example demonstrates.

1) S1: In my picture

2) there is a snow man

3) with a hat

4) and long nose

During the interview, the participants stated that they intentionally used several lines to signal to their partners that they were typing so their partners would know to wait until they had finished a sentence. Therefore, time delay may not work as extra processing time for learners.

Existing literature suggests that the short time delay between the actual initiation of a message and its receipt by the addressee gives learners extra processing time (Dornyei \& Kormos, 1998; Pellettieri, 1999). However, the time delay caused overlapping turns, which appear to cause learners to spend more time and attention figuring out the flow of communication. For example, they had to go back and forth on different topics by asking their own questions and answering interlocutors' questions due to the overlapping turns. Moreover, the lack of meta-linguistic cues made it harder for learners to figure out the sequence of turns. Accordingly, SCMC appears to increase learners' cognitive load rather than lower it. Interviews from this study demonstrate that participants did not benefit from the extra time. Most did not spend their time reviewing and evaluating their linguistic output. As one participant noted, "I didn't have time to look at my sentence again. I was so busy with typing my sentences and reading my partner's sentences.'Thus, learners do not necessarily benefit from time delays when paying attention to linguistic forms. Moreover, relying on the printed transcript of SCMC and the measurement of time by sentences does not give a clear picture for understanding what learners actually attend to and do during interaction.

\subsection{Meaning of Recasts}

In discussing recasts, it is often assumed that when an interlocutor notices the interlocutor's error, he or she is likely to think that the error is problematic and wants to offer correction either explicitly or implicitly. Although 
this may be common in interactions between teachers and students or between native speakers and non-native speakers, participants in this study did not intend to correct their partners' errors even when they noticed them. The recasts were given as part of confirming the content, without any intention of correction. The following example shows that one learner even chose to repeat his partner's errors.

\section{S2: The light is closed}

\section{S3: I can't recognize whether is closed or not.}

In this excerpt, two learners try to describe the lamps in their pictures to each other in order to determine whether or not they have the same images. Both pictures include a lamp on the table. S2 wants to indicate that the lamp's light is off, saying "the light is closed." Although S2 used an inappropriate word (i.e., closed), S3 seems to interpret S2's utterance as "the light is off." S3 responds to S2 saying that he is not sure whether the light is on or off based on his picture, again using the incorrect form "closed." Based on this transcript, both S2 and S3 seemed unaware of their mistakes in word choice. However, data from stimulated recall reveal that S3 was aware of the incorrect use of the word.

I knew his sentence was wrong. But at the same time, I knew what he meant by "light is closed." He meant "the light is off." So, I used his term too. What we were supposed to do at that time was to find differences on pictures. Not a grammar checks... I did not want to correct him or ask questions as long as I could understand his sentences.

This excerpt illustrates that negotiation of meaning does not occur when interlocutors share the meaning, even when the form is not correct. In addition, when learners' attention is focused on the tasks, they may not offer corrective feedback even when aware of errors.

This example highlights the meaning of recasts from the learner's point of view. In this example, S2 noticed S1's non-target form and was aware of the correct form during the online chat. Although he did not want to correct his partner with explicit feedback, he could have answered by stating "I can't recognize whether it is on or not." In other words, his answer could have worked as a recast. However, he opted to use the non-target form to make the conversation flow and make his partner feel comfortable talking. Other learners (87 percent) in this study also commonly reported that they did not care about others' errors. Some participants were strongly against the idea that they may offer corrective feedback to their peers. This may explain in part why non-native speaker dyads do not produce much feedback compared to native-non-native dyads. This may be problematic considering that the leaner who made mistakes did not receive correction for the ill-formed sentences. Yet the learner may have learned how to communicate with others without worrying about making mistakes; indeed, it is important to note that the social interaction during SCMC constitutes learning. Although learners at this moment might have missed the chance to pay attention to linguistic forms, they developed communicational and metacognitive skills by using the $\mathrm{L} 2$ in real-time interactions.

\subsection{Revisiting Recasts: Incidental Recasts}

The negotiation routines found in this study suggest that the type of CMC negotiation is different from face-to-face-face communication. Turn adjacency is not clear in CMC conversations. Accordingly, the triggers for negotiation of meaning often remain unanswered initially. When triggers spark interlocutors' attention, they are answered in subsequent turns or even much later turns. However, some triggers did not initially receive attention, and the conversation moved on to another topic until the same trigger occurred again. Such findings support Smith's (2003) arguments on split negotiation routines. Smith defined split negotiation routines as negotiation routines that "begin with a trigger and are followed by an indicator of non-understanding, whose response may occur after a second (or third) repeat indicator some time later in the discourse" (p. 48).

Similarly, the data from the current study suggest revisiting the definition of recasts. The commonality of split routines often resulted in recasts being provided after a time delay rather than within immediate feedback. Therefore, the traditional definition of a recast is called into question in the SCMC environment. Moreover, the interview with students revealed that most participants who provided recasts to their partners did not do so intentionally. Their recasts often sought to confirm the contents. Because of the characteristics of the tasks, which forced learners to find differences in pictures, learners often had to go back to the same topics or vocabulary to complete the tasks. Accordingly, the target form of an ill-formed utterance was often produced later in the conversation, but not necessarily in direct response to the previous ill-formed utterance.

This issue sheds light on incidental recasts. Ohta (2001) claimed that incidental recasts occur in face-to-face interaction when the learners attend to language of an utterance that is not produced in response to their utterances, but rather coincidentally contrasts with their L2 production. The findings from the current study 
suggest that the potential for incidental recasts as corrective feedback may be more common in SCMC. As previously discussed, the majority of recasts given immediately following learners' problematic utterances were not noticed by learners. However, learners later actively used the target form that contrasted with their own L2 production, even when the target form was not given in response to their ill-formed utterances.

The following excerpt shows such an incidence:

1) S4: man look for the ice man

2) S5: ?

3) S4: home

4) S5: ah. I know

5) S4: sun

6) S5:I see a snowman. ...

[20 lines of additional text]

7) S4: there are hat

8) S5: who?

9) guy or snowman?

10) S4: son man

11) snow man

Thus, in line 1, S4 used the term "ice man," which triggered misunderstanding for S5. In line 2, S5 asked about the meaning of ice man by using a question mark. However, S4 did not notice that S4 was asking about her vocabulary and continued in line 3 to talk about what she had in her picture. In line 4, S4 understood what S4 meant by "ice man," but did not correct S4. Then S5 provided recasts with "snowman" in line 6 . However, S4 did not pay attention to it as linguistic feedback. During the stimulated recall interview, S4 did not recall that her partner was asking for clarification as well as correcting her. S4 said that she was busy listing things she saw in her picture. However, 2 lines later, in line 11, she used "snow man." In the interview, she explained this use, noting "I used the snow man because my partner used it during the task. It seems the right word so I decided to use it."

The occurrence of incidental recast was not found in abundant in this study. Only 8 incidences were observed. However, it suggests that learners still can benefit from task-based online interaction because it gives learners opportunities to compare their interlanguage with target form with visual feedback when they needed. S4 read the interlocutor's utterances in order to respond to him. She needed to read the interlocutor's sentences more carefully in order to answer him. Accordingly, during these processes, learners seem to focus on grammar more carefully. In this situation, the visual saliency gives an additional advantage to learners, helping them note the contrasts between their L2 interlanguage and the model form provided by interlocutors. In other words, visual saliency does not necessarily give an additional advantage to learners in noticing recasts when their focus is on the content of their interlocutor's utterance rather than grammar. Moreover, recasts are likely to be more implicit to learners during SCMC than in face-to face conversations because of the split turns of SCMC and the pressure to follow the flow of conversations.

\section{Conclusion}

The impressive number of studies examining efficacy of SCMC for pedagogical purposes have suggested the perceived pedagogical benefits of SCMC. However, most studies have been limited in that they were carried out using definitions and/or research methodologies adopted from face-to-face interactions. However, using the same approach as face-to-face interactions is not sufficient when investigating SCMC because it cannot deal with the different interactional contexts that SCMC provides. The appropriate exploration of the efficacy of SCMC for pedagogical purposes can be done through careful investigation of potentially beneficial, inherent attributes of SCMC.

This study provides some empirical evidence for the capacity of task-based SCMC to provide corrective feedback and enhance learners' noticing of their own errors. However, the target of corrective feedback and self-correction is called into question regarding the provision of pedagogical implications. Furthermore, this study found that learners can benefit from incidental recasts that coincidentally contrasted with their ill-formed L2 production during SCMC. This learning opportunity during SCMC has not been reported in most previous 
studies, which have relied on learner uptake while neglecting their perception.

Findings from this study also challenge the previous assumptions about certain SCMC features that are believed to be beneficial to learners. Learners did not feel that they had more time to process and monitor their interlanguage. Rather, features like typing and split turns increased learners' cognitive load and made them feel pressure during the interaction. In addition, learner uptake during SCMC was low because learners felt unnatural typing sentences in order to respond to recasts; typing the sentence again is redundant even when a correction to the sentence is made.

Given the descriptive nature of this study, generalizations of these results should not be made to other populations. It would be interesting to investigate the interaction between ESL learners and native speakers since their attitude and attention would be different. In addition, further research should examine learners' actual behaviors during the processing time. Such studies will inform researchers and educators in an effort to integrate technology into the language classroom.

\section{References}

Braidi, S. M. (1995). Reconsidering the role of interaction and input in second language acquisition. Language learning, 45, 141-175.

DeBell, M., \& Chapman, C. (2003). Computer and Internet use by Children and Adolescents in the United States, 2001 (NCES 2004-014). Washington, DC: U.S. Department of Education, National Center for Education Statistics.

Dörnyei, Z., \& Kormos, J. (2000). The role of individual and social variables in task performance. Language Teaching Research, 4, 275-300.

Ellis, R., \& Sheen, Y. (2006). Reexamining the role of recasts in second language acquisition. Studies in Second Language Acquisition, 28, 575-600.

Ericsson, K. A., \& Simon, H. A. (1993). Protocol analysis: Verbal reports as data (revised edition). Cambridge, MA: Bradford books/MIT Press.

Gass, S., \& Mackey, A. (2000). Stimulated Recall Methodology in Second Language Research. Mahwah, NJ: Lawrence Erlbaum.

Iwasaki, J., \& Oliver, R. (2003). Chat-line interaction and negative feedback. An Occasional Thematic Issue of the Australian Review of Applied Linguistics (ARAL) (pp. 60-73).

Kim, Y. (1998). The effect of a networked computer-mediated discussion on subsequent oral discussion in the ESL classroom (Unpublished doctoral dissertation). University of Texas at Austin.

Kitade, K. (2000). L2 learners' discourse and SLA theories in CMC: Collaborative interaction in internet chat. Computer Assisted Language Learning, 143-166. http://dx.doi.org/10.1076/0958-8221(200004)13:2;1-D;FT143

Lai, C., Fei, F., \& Roots, R. (2008). The contingency of recasts and noticing. The CALIOCO Journal, 26(1), 70-90.

Lai, C., \& Zhao, Y. (2006). Noticing and text-based chat. Language Learning and Technology, 10(3), 102-120.

Loewen, S., \& Erlam, R. (2006). Corrective Feedback in the Chatroom: An experimental study. Computer Assisted Language Learning, 19, 1-14. http://dx.doi.org/10.1080/09588220600803311

Mackey, A., Gass, S. M., \& McDonough, K. (2000). How do learners perceive interactional feedback? Studies in Second Language Acquisition, 22, 471-497.

Ohta, A. (2001). Second language acquisition processes in the classroom: Learning Japanese. Mahwah, NJ: Lawrence Erlbaum.

Oliver, R., \& Mackey, A. (2003). Interactional context and feedback in child ESL classrooms. The Modern Language Journal, 87(4), 519-533.

Pellettieri, J. (1999). Negotiation in cyberspace: The role of chatting in the development of grammatical competence. In M. Warschauer, \& R. Kern (Eds.), Network-based language teaching: Concepts and practice (pp. 59-86). Cambridge: Cambridge University Press.

Pellettieri, J. (2000). Negotiation in cyberspace: The role of chatting in the development of grammatical competence. In M. Warschauer, \& R. Kern (Eds.), Network-based language teaching: Concepts and practice (pp. 59-86). New York: Cambridge University Press. 
Pica, T., Kanagy, R., \& Falodun, J. (1993). Choosing and using communication tasks for second language instruction and research. In G. Crookes, \& S. Gass (Eds.), Tasks and language learning: Integrating theory and practice (pp. 9-34), Clevedon, UK: Multilingual Matters.

Sheen, Y. (2004). Corrective feedback and learner uptake in communicative classrooms across instructional settings. Language Teaching Research, 8, 263-300.

Smith, B. (2003). Computer-mediated negotiated interaction: An expanded model. The modern Language Journal, 87, 38-57.

Smith, B. (2004). Computer-mediated negotiated interaction and lexical acquisition. Studies in Second Language Acquisition, 26, 365-398.

Smith, B. (2005). The Relationship between Negotiated Interaction, Learner Uptake, and Lexical Acquisition in Task-Based Computer-Mediated Communication. TESOL Quarterly, 39, 33-58.

Tarone, E. (2009). A sociolinguistic perspective on interaction in SLA. In A. Mackey, \& C. Polio (Eds.), Multiple perspectives on interaction: Second language research in honor of Susan M. Gass (pp. 41-56). New York: Routledge.

Tudini, V. (2007). Negotiation and intercultural learning in Italian native speaker chat rooms. The Modern Language Journal, 91(4), 577-601.

Warschauer, M. (1996). Comparing face-to-face and electronic discussion in the second language classroom. CALICO Journal, 13, 7-26.

\section{Copyrights}

Copyright for this article is retained by the author(s), with first publication rights granted to the journal.

This is an open-access article distributed under the terms and conditions of the Creative Commons Attribution license (http://creativecommons.org/licenses/by/3.0/). 